\title{
Continuous Dynamic Monitoring of Lively Footbridges
}

\author{
http://dx.doi.org/10.3991/ijoe.v12i04.5136 \\ E. Caetano, A. Cunha and C. Moutinho and W.-H. Hu \\ University of Porto, Porto, Portugal
}

\begin{abstract}
The paper describes two dynamic monitoring systems installed in lively footbridges with the purpose of characterizing the dynamic behavior and response of these structures and possibly detecting damage at early stages. Some monitoring results illustrate the capabilities of the presently existing technology.
\end{abstract}

Index Terms-automatic identification; dynamic monitoring; footbridges; modal parameters; vibrations.

\section{INTRODUCTION}

Vibration-based Structural Health Monitoring (SHM) techniques have been increasingly used in lively footbridges with the following main purposes: the verification of serviceability limits under pedestrian excitation; the assessment of the efficiency of implemented vibration mitigation measures; and the early assessment of damage [1-3]. In this context and during the last decade, the Laboratory of Vibrations and Monitoring (ViBest, www.fe.up.pt/vibest) of the Faculty of Engineering of University of Porto (FEUP) has carried out an extensive research program on this theme, which led to the implementation of continuous dynamic monitoring systems in two lively footbridges [4-6]. This paper discusses the main features of the implemented monitoring systems, namely as regards the instrumentation and data acquisition, the algorithms for automatic identification of modal parameters and the techniques for assessment of damage.

\section{DyNAMIC PROPERTIES OF LIVEly FoOTBRIDGES}

In order to specify the characteristics of the instrumentation, the requirements of the data acquisition system and the algorithms for identification of modal properties and detection of damage, it is necessary to define the general characteristics of the structures that are the object of the present study.

Modern footbridges are typically lightweight structures exhibiting fundamental natural frequencies ranging from less than $0.5 \mathrm{~Hz}$ to more $10 \mathrm{~Hz}$, depending on the span length. These structures are also lightly damped and therefore they can be prone to vibrations induced both by the wind and by the action of pedestrians. Long span footbridges, with central spans greater than $100 \mathrm{~m}$, may have a series of natural frequencies lower than $1 \mathrm{~Hz}$, and exhibit vulnerability to wind excitation. Spans of the order of 80 $\mathrm{m}$ to $120 \mathrm{~m}$ are normally characterized by lateral modes with frequencies in the range of $0.5 \mathrm{~Hz}$ to $1.2 \mathrm{~Hz}$, which can easily be excited by pedestrians and lead to important feedback phenomena, designated as lateral synchronization or lock-in. Spans greater than $30 \mathrm{~m}$ can have natural frequencies of $1.5 \mathrm{~Hz}$ to $4 \mathrm{~Hz}$, which can be easily excited vertically by walking, jogging and running pedestrians.
The above described frequency ranges that are critical from the points of view of wind and pedestrian lateral and vertical excitations define an interval of interest for measurement of $0.3 \mathrm{~Hz}$ to $10 \mathrm{~Hz}$, although in fact one can expect that higher structural frequencies are present, both due to the structural behavior and environmental noise.

As regards the expected amplitude of vibrations, the basis for selection of instrumentation is the consideration of the limits for intolerable acceleration, which correspond to $0.8 \mathrm{~m} / \mathrm{s}^{2}$ and $1.8 \mathrm{~m} / \mathrm{s}^{2}$ for lateral and vertical directions, respectively. It is known however that lively footbridges can reach very high amplitudes, of the order of $10 \mathrm{~m} / \mathrm{s}^{2}$ under jumping, bouncing and vandal excitations. The choice of sensor sensitivity should be made considering these amplitudes. At the same, if the purpose of the monitoring system is also to detect damage, it is required that the structural response is recorded continuously, that is both when the structure is being excited by pedestrians and when it is empty and the ambient response is very low. So the chosen accelerometers should be able to capture amplitudes of the response of $0.05 \mathrm{~m} / \mathrm{s}^{2}$ to $10 \mathrm{~m} / \mathrm{s}^{2}$.

This publication is centered on two lively footbridges located in Portugal that were object of the implementation of SHM systems. The first structure is a stress-ribbon footbridge linking the main buildings of the Faculty of Engineering of the University of Porto (FEUP) with the students' canteen (Figure 1), formed by two continuous spans of $28 \mathrm{~m}$ and $30 \mathrm{~m}$ long and characterized by two natural frequencies very close to $2 \mathrm{~Hz}$, which are typical of those associated with the pedestrian walking. Consequently, the footbridge experiences frequently relevant levels of vertical vibration.

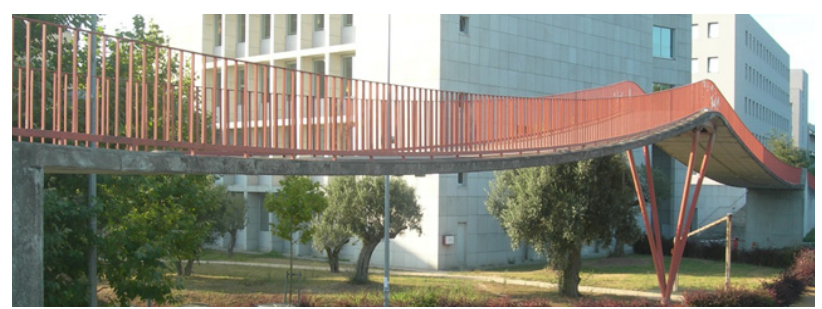

Figure 1. FEUP footbridge, general view.

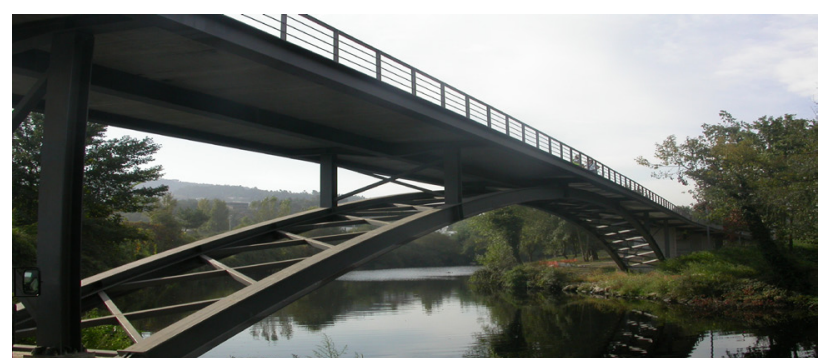

Figure 2. Footbridge at Parque da Rabada, Santo Tirso. 
The second footbridge, formed by a steel arch with 60 $\mathrm{m}$ chord and $6 \mathrm{~m}$ rise (Figure 2 ), has shown to exhibit also relevant vertical vibrations under crowd and jogging loads, what motivated the installation of a passive control system based on two tuned mass dampers (TMDs) for frequencies of about $1.6 \mathrm{~Hz}$ and $2.7 \mathrm{~Hz}$.

\section{Characteristics OF INSTALlED SHM SySTEMS}

The SHM systems installed in both footbridges were designed to characterize vibration levels, to detect damage and, in the case of the arch footbridge, to check the good performance of the TMDs.

In order to select the number and disposition of sensors required to capture the most relevant response, baseline ambient vibration tests were conducted in both footbridges. Figures 3 and 4 display the first identified relevant frequencies and vibration modes for the two footbridges.

In the case of the FEUP footbridge, the dynamic monitoring system is based on four sensor units. Each unit comprises a vertical accelerometer PCB-393C, a signal conditioner PCB-488A03 and a thermal sensor PT100. These sensors are mounted separately on the lower surface of the bridge deck at both $1 / 2$ and $1 / 3$ of each span (Figure 5 (a) and (b)). Acceleration signal conditioners and thermal sensors are connected via cable with National Instruments Ethernet data acquisition (DAQ) devices, which are inserted in a steel box installed beneath the deck at the intermediate support (Figure 5 (b)). The NI Ethernet DAQ unit consists of a data acquisition device NI ENET-9215 transmitting output acceleration signals with a sampling frequency of $5 \mathrm{kHz}$ under operational conditions, and an universal input device NI ENET-9219, acquiring temperature with a sampling frequency of $1 \mathrm{~Hz}$, both carriers being connected to an Ethernet switch, which transmits acquired data into a computer at FEUP through a powerline bridge. The NI Ethernet DAQ device is driven by a signal acquisition toolkit, which decimates acceleration signals to $50 \mathrm{~Hz}$, generating a nearly real-time zipped acceleration signal file every 10 minutes and a temperature file every 30 minutes continuously. All signal files acquired under operational conditions are conveniently accessed via Internet. The continuous dynamic monitoring system has been operating since the 1 st of June 2009, with occasional flaws due to small technical problems. In order to obtain accurate estimates of structural properties, six consecutive 10 minute signal files are concatenated to one hour response series.

In the case of the Parque da Rabada footbridge, the monitoring system comprises 7 accelerometers and 4 thermal sensors. According to the representation of Figure 6 (a), 3 of the accelerometers measure directly the vibration of the deck and the other 4 accelerometers are installed on the masses that form the two implemented TMDs. Thermal sensors are also installed to measure temperature at two sections of the deck, and are placed on the surface between the concrete slabs and the respective metallic supporting structure.

The acquisition system consists of a compact chassis integrating two 4-channel acquisition boards for accelerations and one 4-channel board for thermal sensors (Figure 6 (b)). The chassis is controlled by a computer installed in an observation post located in one of the lateral concrete columns of the structure (Figure 6(c)). The communication between these instruments is achieved with 2 powerlines
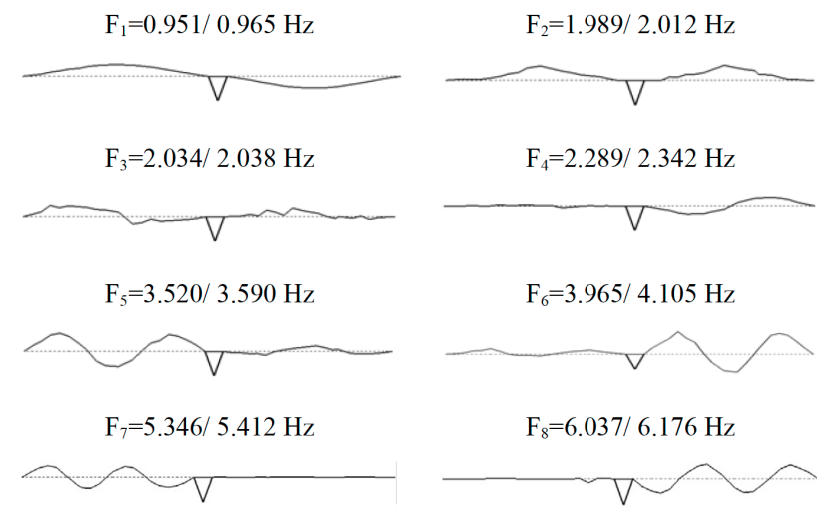

Figure 3. FEUP footbridge: identified mode shapes.
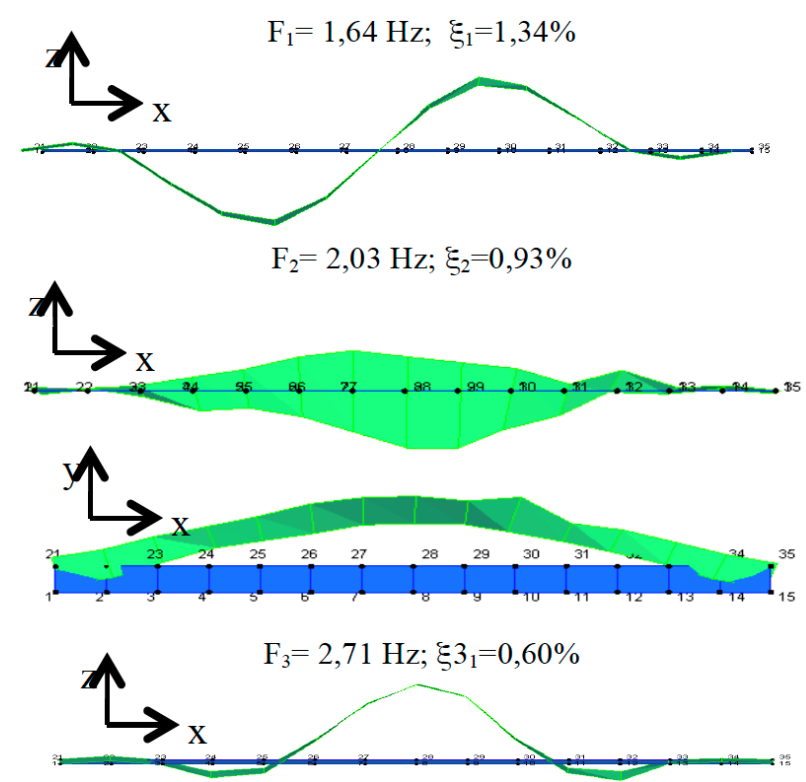

Figure 4. Parque da Rabada footbridge: identified mode shapes.

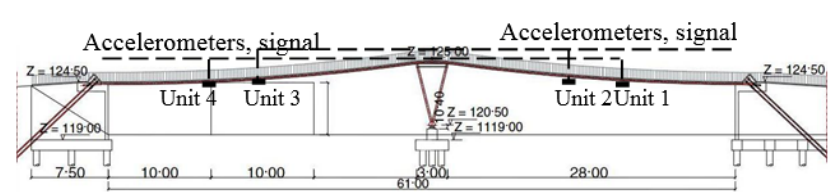

(a)

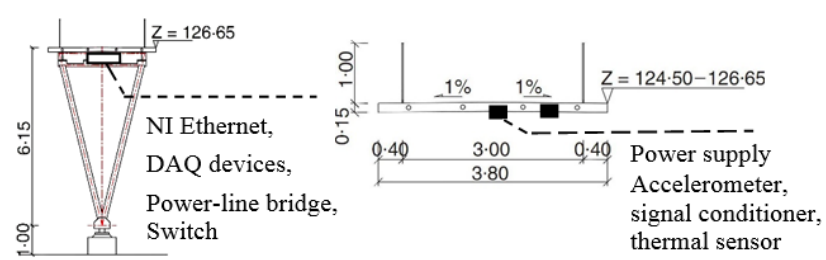

(b)

Figure 5. FEUP footbridge: (a) Elevation with instrumentation layout;

(b) Section over column and instrumented cross-section.

that enable the data transfer using the electrical installation of the bridge. The communication system for local data transfer or for remote transfer of files to FEUP is also located in that box.

Continuously monitored data are organized in two types of files, respecting acceleration and temperature records. The signals measured by the seven accelerometers are acquired for 10-minute periods at a sampling frequency of $2 \mathrm{kHz}$. These records are band-pass filtered, re-sampled at 


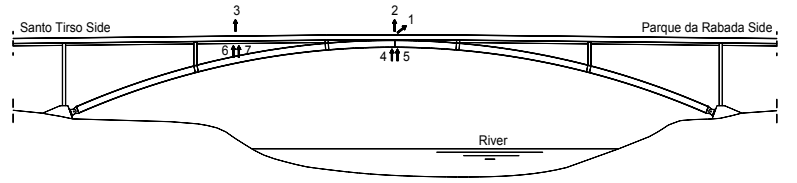

(a)

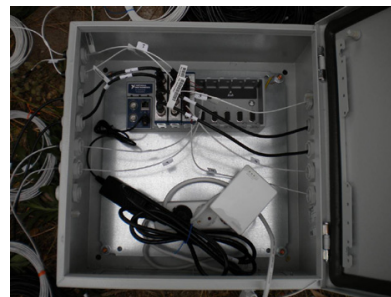

(b)

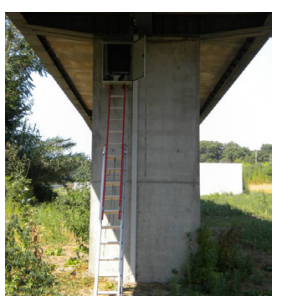

(c)
Figure 6. Parque da Rabada footbridge: (a) Location and direction of installed accelerometers; (b) Compact data acquisition system; (c) Observation post.

$50 \mathrm{~Hz}$ and stored in the local hard disc. In each day, 144 files containing 7 columns of acceleration time series are produced, with a total size of $40 \mathrm{Mbytes}$. Temperature records are collected at the four channels at a sampling rate of $1 \mathrm{~Hz}$ for periods of 30 minutes. In this case, 48 files are produced every day, with a size of 1 Mbyte.

In order to track the variation of modal properties in both footbridges, a Continuous Structural Modal Identification (CSMI) toolkit has been developed and implemented in LabVIEW environment, which runs automatically without any manual interaction [6,7].

With occasional flaws, the two monitoring systems have been in continuous operation since June 2009, in the case of the FEUP footbridge, and since June 2012, in the case of the Parque da Rabada Bridge. A demonstration of the automatic processing and access has been presented in [8]. In that demonstration, results of the automatic analysis of data have been shown for the monitored footbridges, to illustrate the potential of continuous dynamic monitoring. These comprehend statistics of the measured accelerations, time variations of automatically identified modal parameters (natural frequencies and modal damping ratios), correlations between natural frequencies and temperatures and amplitudes of vibration and intervals of time of activation of TMDs, in the case of the Parque da Rabada footbridge.

\section{Conclusions}

The two dynamic monitoring systems provide an example of the use of state-of-art developments in data acquisition and communications in the serviceability characterization of lively footbridges, illustrating the immense potential of on-line monitoring in the assessment of environmental and operational effects and in the characterization of vibration intensity and damage in the context of civil engineering applications.

\section{REFERENCES}

[1] Cunha, A., Caetano, E., Magalhães, F. \& Moutinho, C. Recent perspectives in dynamic testing and monitoring of bridges. J. Structural Control and Health Monitoring 2013, Vol.20, Issue 6, pp.853-877. http://dx.doi.org/10.1002/stc. 1516

[2] Peeters B, De Roeck G.. One-year monitoring of the Z24-Bridge: environmental effects versus damage events. Earthquake Engineering and Structural Dynamics 2001, 30(2), 149-171. http://dx.doi.org/10.1002/1096-9845(200102)30:2<149::AIDEQE1>3.0.CO;2-Z

[3] Deraemaeker A, Reynders E, De Roeck G., Kullaa J. Vibrationbased structural health monitoring using output-only measurements under changing environment. Mechanical Systems and Signal Processing 2008, 22(1), 34-56. http://dx.doi.org/10.1016/ j.ymssp.2007.07.004

[4] Hu, W.-H., Moutinho, C., Caetano, E., Magalhães, F. \& Cunha, A. Continuous dynamic monitoring of a lively footbridge for serviceability assessment and damage detection. Mechanical Systems and Signal Processing 2012, Vol. 33, pp. 38-55 http://dx.doi.org/10.1016/j.ymssp.2012.05.012

[5] Caetano, E., Moutinho, C. \& Cunha, A. Implementation and monitoring of a passive control system in a lively footbridge. Int. Conf. on Integrity, Reliability and Failure, IRF'2013, Funchal, Madeira, Portugal.

[6] Hu W-H, Cunha A, Caetano E, Magalhães F, Moutinho C. LabVIEW Toolkits for Output-only Modal Identification and Longterm Dynamic Structural Monitoring. Structure and Infrastructure Engineering: Maintenance, Management, Life-Cycle Design and Performance 2010, 6(5), 557-574. http://dx.doi.org/10.1080/15732 470903068672

[7] $\mathrm{Hu} \mathrm{W}-\mathrm{H}$. Operational modal analysis and continuous dynamic monitoring of footbridges. Ph. D. Thesis. 2011, Faculty of Engineering, University of Porto.

[8] [8] Caetano, E., Cunha, A., Moutinho, C. \& Hu, W. Dynamic monitoring of lively footbridges, $3^{\text {rd }}$ Experiment@ International Conference, Demo Session, 2 nd $-4^{\text {th }}$ June 2015, Azores.

\section{AUTHORS}

E. Caetano, A. Cunha and C. Moutinho are with the Faculty of Engineering of the University of Porto (FEUP), R. Dr. Roberto Frias, 4200-265 Porto PORTUGAL (emails: ecaetano@fe.up.pt; acunha@fe.up.pt; moutinho@fe.up.pt). They are also members of the Laboratory of Vibrations and Monitoring (ViBest) at FEUP.

W. $-\mathbf{H}$. Hu is member of the Laboratory of Vibrations and Monitoring (ViBest) at FEUP and was formerly Ph.D. Student at this University (e-mail: weihuahu@foxmail.com).

This work was supported in part by the National Science Foundation (FCT) in the context of the projects "Wind analysis of special structures from full scale measurements" and "DYNAMO_DEMO - Advanced Tools for Dynamic Structural Health Monitoring of Bridges and Special Structures". Submitted, 09 March 2015. Published as resubmitted by the authors on 09 April 2015. 